\title{
The Impact of Liberalization on the Production of Electricity in Japan: Stochastic Frontier Analysis*
}

\author{
Miyuki Taniguchi \\ Graduate School of Economics, Keio University, Tokyo, Japan \\ Email: miyuki@z3.keio.jp
}

Received 30 January 2014; revised 5 March 2014; accepted 12 March 2014

Copyright (C) 2014 by author and Scientific Research Publishing Inc.

This work is licensed under the Creative Commons Attribution International License (CC BY).

http://creativecommons.org/licenses/by/4.0/

(c) (i) Open Access

\section{Abstract}

This study aims to measure the impact of liberalization on the efficiency of electricity production in Japan using Stochastic Frontier Analysis (SFA). In addition, this study also aims to examine whether or not economies of scale exist in the electricity generation sector and the transmission sector, and whether or not economies of scope exist between electricity generation and transmission. Since 1995, liberalization of the electricity market in Japan has been phased in and regulations on entry have been relaxed three times. One motivation for these regularity changes has been to improve the efficiency of electricity production by introducing competition. Using a panel data set on the nine main power companies in Japan over the period 1970-2010, estimates of fixed-effects and stochastic frontier models of the cost function are obtained and compared. Estimates of the cost function show that liberalization has improved cost efficiency when both frontier models and non-frontier models are estimated. Estimates of the fixed-effects model are used to calculate economies of scale and economies scope because the data support the fixed-effects model. Economies of scope are found to exist for all nine power companies, while overall economies of scope declined in the 1970s and have improved little by little since the 1980s.

\section{Keywords}

Cost Function; Electricity; Liberalization; Stochastic Frontier Analysis; Economies of Scope; Vertical Integration

\footnotetext{
"This paper is based a presentation at the International Conference on Applied Economics 2014 (Taniguchi (2013b) [1]). An earlier version of this paper has appeared as a discussion paper (Taniguchi (2013a) [2]).
} 


\section{Introduction}

Recently inefficiencies in the Japanese electricity market have been the focus of some attention. In particular, even though the liberalization of the electricity market has been phased in and regulations on entry have been relaxed three times since the 1990s, the monopolistic nature of the Japanese electricity market has been the subject of much discussion since the Management and Coordination Agency in Japan (Soumu-cho) proposed enegry liberalization (the official website of Federation of Electric Power Companies of Japan:

http://www.fepc.or.jp/enterprise/jiyuuka/keii/). There has also been some discussion of the possible separation of electricity generation and transmission. For example, Goto and Inoue (2012) measure the economies of scope between generation and transmission in Japan to examine the effectiveness of diversification in the Japanese electricity industry [3]. This study aims to measure the impact of recent liberalizations on the efficiency of electricity production in Japan, and to examine whether or not economies of scope exist between electricity generation and transmission.

A huge literature has examined whether or not inefficiencies exist in various industries including the electricity industry. Papers using a parametric approach tend to estimate a cost function rather than a production function because there are endogeneity problems associated with input choices when estimating a production function. To estimate either a production function or a cost function, papers in the literature use either a parametric approach or a non-parametric approach. Papers using a non-parametric approach typically employ Data Envelopment Analysis (DEA) to measure the inefficiencies among the electricity companies. Papers using DEA measure either productive efficiencies or cost efficiencies, using the variables which are the same as the variables to estimate either the production function or cost function.

For the electricity industry in Japan, there are three key papers using parametric approach. Using data from 1978 to 1998, Kuwabara and Ida (2000) estimate a translog cost function for the Japanese electric companies together with share equations [4]. Kuwabara and Ida (2000) aim to measure the extent of economies of scale and economies of scope in the electricity industry in Japan, but they do not examine the impact of the liberalization measures that have been implemented. Their results support the existence of both overall economies of scale and economies of scope for all electric power companies during the period Kuwabara and Ida analyzed. Using data from 1982 to 1997, Nemoto and Goto (2006) estimate a constant elasticity of substitution (CES) cost function, and measure the technical and allocative efficiencies of the transmission-distribution of electricity in Japan [5]. Their results show the existence of technical and allocative inefficiency. The observed costs are estimated to be from $9 \%$ to $48 \%$ higher than their efficient levels. Kinugasa (2012) measures the Lerner index for each Japanese electric company to examine whether three liberalizations have made the market more competitive using estimates of translog production functions [6]. Kinugasa's (2012) empirical results show that the three liberali- zations have made every electricity market more competitive. Goto and Inoue (2012) estimate a composite cost function for the Japanese electric companies using data between 1990 and 2008 [3]. Goto and Inoue do not use the translog cost function, but rather use a composite cost function which enables them to measure the economies of vertical integration, which includes both the effects of economies of scale and economies of scope, in electricity production. They reports that there were no overall economies of scale and that there were economies of scope. In detail, the economies of scale for generation existed during their sample period, while economies scale for transmission did not exist.

For the electricity industry in Japan, there are two key papers using the DEA approach. Tsutsui (2000) measures the inefficiencies of Japanese electric companies using the Malmquist Index, and then compares the estimated inefficiencies of Japanese electric power companies with those of the US companies between 1992 and 2000 [7]. Although his results show that Japanese firms are more efficient than US firms, Tsutsui does not examine the impact of the electricity liberalization. One disadvantage of the DEA approach is that the statistical significance of the input variables cannot be evaluated. Hence, the impact of any liberalization cannot be examined via the DEA statistically. Hattori, Jamasb, and Pollitt (2005) measure the efficiencies of electricity distribution in the UK and Japan between 1985 and 1998, using not only stochastic frontier analysis (SFA), but also DEA [8]. Their results show that the Japanese electricity system is less efficient than the UK system. Their data period contains only the first electricity liberalization in Japan though Japan experienced three electricity liberalizations in total up to now.

As can be seen from this brief literature survey, the impact of the relaxation of entry restrictions on the inefficiency of Japanese electric companies has not been examined to date using the SFA approach. The first contri- 
bution of this study is to examine the impact of the liberalization in the Japanese electricity market by estimating a translog cost function directly. The second contribution of this paper is to measure the economies of scale and the economies of scope, using estimates of this translog cost function. As a result, the hypothesis that the three electricity liberalizations contribute to reducing the cost of electricity generation and transmission is supported. This result is consisted with Kinugasa (2011) [6]. The estimates of the overall economies of scale and the economies of scope in this paper are consisted with the results in Goto and Inoue (2012) [3]. The estimated results of this paper suggest that overall economies of scale did not exist and economies of scope existed.

The rest of this paper is organized as follows. Section 2 provides an outline of the key liberalizations of the electricity market that have been implemented in Japan. Section 3 discusses the empirical models that are used to examine the impact of these liberalizations and how this model can be used to check for the existence of economies of scope between electricity generation and electricity transmission, while Section 4 details the definitions of the variables used and the data sources. Estimation results are reported in Section 5, and Section 6 contains a conclusion.

\section{Liberalization of the Electricity Market}

In the 1990s, deregulation to reduce inefficiencies in the electricity market was popular all over the world. At that time, many European countries and the United States deregulated their electricity markets. Since 1995, liberalization of the electricity market in Japan has been phased in and the regulations on entry have been relaxed three times. This liberalization aimed to improve the structural efficiency of firms in the industry and to reduce electricity bills that were said to be higher than the average level paid by consumers in foreign countries (Yamaguchi (2007) [9]).

Table 1 summarises the details of the main changes in the electricity market as a result of the liberalizations. Prior to 1995, Japan was divided into ten geographic regions, and within each region a monopoly on power generation and distribution was allocated to one general electric power utility (GEU, Ippan Denkijigyousha). As a result, there are ten general electric power utilities in Japan [9]. These ten companies each engaged in the generation, transmission and distribution of electricity within their respective geographical regions. Apart from GEUs, only wholesale electric power utilities (WEU, Oroshiuri Denkijigyousha) were allowed to generate electric power that was then supplied to GEUs. Only two WEUs existed; the Electric Power Development Company Limited (Dengenkaihatsu) and the Japan Atomic Power Company (Nihon Genshiryokuhatsuden). Both companies were started with capital from the GEUs. Private power generation (PPG) was also allowed. In other words, the electricity generation was allowed as long as they sell the electric power to the others. After the collapse of Japan's overheated stock and real estate markets in the early 1990s, higher electricity bills in Japan compared to those paid by consumers in foreign countries became an issue. The Japanese government aimed to improve the efficiency of electricity production by introducing competition into the electric power market.

Table 1. The main points of revisions of the electricity business act.

\begin{tabular}{|c|c|c|c|c|c|c|}
\hline \multirow{2}{*}{ Year } & \multirow{2}{*}{ Generation } & \multirow{2}{*}{$\begin{array}{c}\text { Wholesale } \\
\text { Market }\end{array}$} & \multirow{2}{*}{$\begin{array}{l}\text { Distribution } \\
\quad \& \text { Sales }\end{array}$} & \multicolumn{2}{|c|}{ Liberalized Retail Market } & \multirow{2}{*}{ The Other } \\
\hline & & & & Lighting Sector & Industry Sector & \\
\hline \multirow{3}{*}{ January, 1970-March, 1995} & GEU & & GEU & No change & No change & No change \\
\hline & WEU & WEU & & & & \\
\hline & PPG & PPG & & & & \\
\hline \multirow{4}{*}{ April, 1995-February, 1999} & GEU & & GEU & & & \multirow{7}{*}{ SEU } \\
\hline & WEU & WEU & & & & \\
\hline & PPG & PPG & & & & \\
\hline & WS (IPP etc.) & WS (IPP etc.) & & & & \\
\hline March, 2000-March, 2003 & \multirow{3}{*}{$\begin{array}{c}\text { GEU } \\
\text { WEU } \\
\text { PPG } \\
\text { WS (IPP etc.) }\end{array}$} & \multirow{3}{*}{$\begin{array}{c}\text { WEU } \\
\text { PPG } \\
\text { WS (IPP etc.) }\end{array}$} & \multirow[t]{2}{*}{ GEU } & & Over 2000 kW & \\
\hline April, 2004-March, 2005 & & & & & Over 500 kW & \\
\hline April, 2005- & & & PPS & & Over $50 \mathrm{~kW}$ & \\
\hline
\end{tabular}

Source: constructed by the author based on information on Tokyo Electric's website (http://www.tepco.co.jp). 
First, the Electricity Business Act (Denkijigyouhou) was revised to enable wholesale suppliers (WS) to enter the wholesale markets for electricity supply. This revision was enacted in December 1995. The typical example of a WS is an independent power producer (IPP, Dokuritsukei Hatsudenjigyousha). IPPs include not only the subsidiaries of GEUs but also companies like steel companies which have the knowhow to generate electric powers. In this context, the wholesale market for electricity refers to the generation of electricity in Japan. The electricity generated by the new entrants was sold to the general power companies, and then supplied to consumers through the transmission sectors owned and operated by the general electricity utilities. Since the first revision of the Electricity Business Act, the specified electricity utilities (SEU, Tokutei Denkijigyousha), who have a duty to generate, distribute, and sell electricity only for the specified areas, have started to generate and distribute electricity. However, the area served by a SEU has been an independent market.

In March 2000, the Electricity Business Act was revised again so that power producer and suppliers (PPS, Tokuteikibo Denkijigyousha) could enter the retail markets for electricity, that is, PPS could sell electricity directly to consumers. This revision permitted new entry of suppliers into the retail market for electricity for consumers with an electric power contract of over $2000 \mathrm{~kW}$. The remaining part of the retail market, that is, for small contract consumers, was maintained as a monopoly of the relevant regional electric power company. That is why this second revsion is called a partial liberalization.

In 2003, the Electricity Business Act was revised to allow entry in April 2004 into the retail market where each consumer's electric power contract was over $500 \mathrm{~kW}$, and then where each consumer's electric power contract was over $50 \mathrm{~kW}$ in April 2005. In short, this revision expanded the sections of the retail market where the PPSs could enter. That is why this is called an expansion of the partial liberalization. Moreover, the market rules for the electricity transmission sector and a watchdog organization (Souhaidengyoutou Gyomushienkikan) have been established to realize fair deals.

An examination of how the retail market shares of various operators have changed after the electricity liberalization began shows that the maximum market share of the PPSs was $0.74 \%$ after the PPS entered the retail market ([10], p. 32). The ten main electric power companies have been able to maintain a market share of $70 \%$ $80 \%$ even after the electricity liberalization ([10], p. 32). However, as a result of new entry, electricity prices have fallen. After the electricity liberalization began, average prices have tended to decline. This fact suggests that the existence of innovation by competition might have led to lower prices.

Figure 1 shows declines in the average electricity prices for households and industry around the time of the liberalizations. After the first electricity liberalization, the average electricity prices for households and industry tend to decline. Though Figure 1 suggests that all of three liberalizations seemed to be effective, there is a possibility that innovation in electric power generation affects electricity prices. Therefore, in the next section, the impacts of these three-step-liberalizations on the production of electricity are examined, using an econometric model.

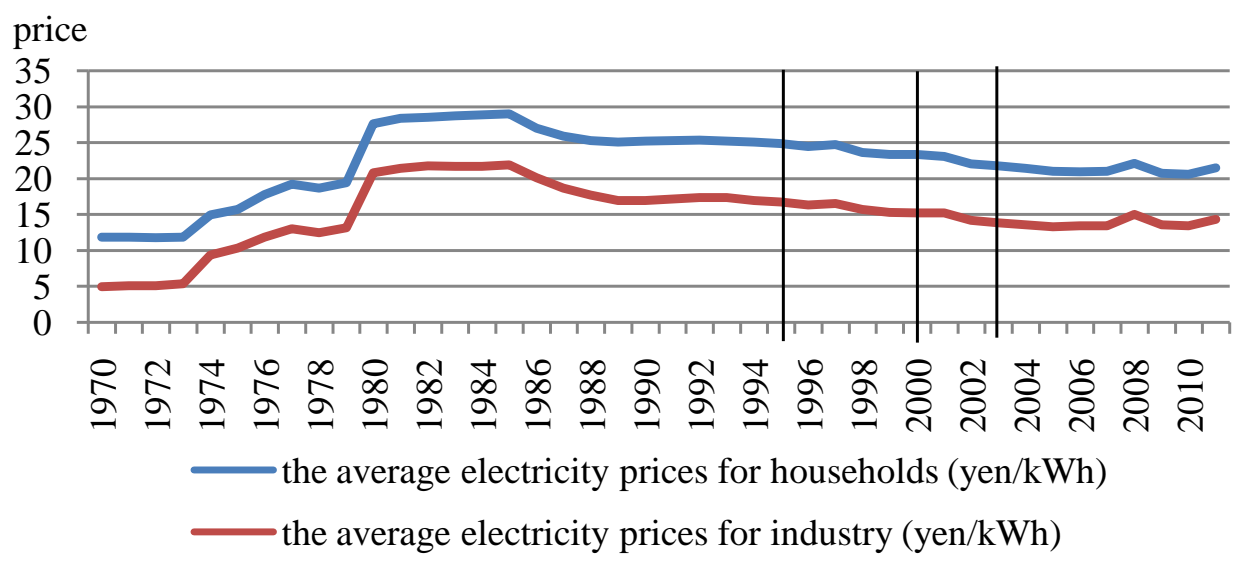

Figure 1. Average electricity prices. Source: constructed by the author using data from the "Electricity Statistics Information (Denryoku Toukeijouhou)" published by the Federation of Electric Power Companies of Japan. Notes: the three vertical lines show the years when the three electricity liberalizations were enacted. 


\section{Model}

\subsection{Translog Frontier Cost Function}

Assume that in the generation, transmission and distribution of electricity there are three inputs, labor, capital and fuel, and two outputs, the generation of electricity, and the transmission and distribution of electricity. These inputs and outputs are assumed to be related by a translog cost function. The number of inputs and the number of outputs are defined following Goto and Inoue (2012) [3]. The outputs are measured as the total quantity electric power sold in a fiscal year and the total length of transmission routes, respectively. This assumption makes it easier to estimate the economies of scope between the generation and transmission \& distribution sectors. To measure the inefficiency due to technical factors, a stochastic frontier version of the translog cost function is employed. Once the symmetry of the second derivatives of the cost function with respect to two different input prices is taken into account, the stochastic frontier translog cost function can be written as follows:

$$
\begin{aligned}
\ln T C_{i t}= & \alpha_{0}+\alpha_{1} \ln y_{1 i t}+\alpha_{2} \ln y_{2 i t}+\beta_{1} \ln p_{1 i t}+\beta_{2} \ln p_{2 i t}+\beta_{3} \ln p_{3 i t}+\gamma_{11} \frac{1}{2}\left(\ln y_{1 i t}\right)^{2}+\gamma_{22}\left(\ln y_{2 i t}\right)^{2} \\
& +\gamma_{12} \ln y_{1 i t} \ln y_{2 i t}+\delta_{11} \frac{1}{2}\left(\ln p_{1 i t}\right)^{2}+\delta_{22} \frac{1}{2}\left(\ln p_{2 i t}\right)^{2}+\delta_{33} \frac{1}{2}\left(\ln p_{3 i t}\right)^{2}+\delta_{12} \ln p_{1 i t} \ln p_{2 i t} \\
& +\delta_{23} \ln p_{2 i t} \ln p_{3 i t}+\delta_{31} \ln p_{3 i t} \ln p_{1 i t}+\rho_{11} \ln y_{1 i t} \ln p_{1 i t}+\rho_{12} \ln y_{1 i t} \ln p_{2 i t}+\rho_{13} \ln y_{1 i t} \ln p_{3 i t} \\
& +\rho_{21} \ln y_{2 i t} \ln p_{1 i t}+\rho_{22} \ln y_{2 i t} \ln p_{2 i t}+\rho_{23} \ln y_{2 i t} \ln p_{3 i t}+\tau_{1} D_{1 t}+\tau_{2} D_{2 t}+\tau_{3} D_{3 t}+\ln t \\
& +\varphi_{\text {thermal }} \text { thermal } \\
& \quad \varphi_{\text {nuclear }} \text { nuclear }{ }_{i t}+\varphi_{\text {new }} n e w_{i t}+u_{i t}+v_{i t} \\
& \ln T C_{i t}=f(\cdot)+u_{i t}+v_{i t},
\end{aligned}
$$

where $T C_{i t}$ is the total cost of the $i$-th firm at time $t, y_{j i t}$ is the quantity of the $j$-th output for the $i$-th firm at time $t, \quad p_{k i t}$ is the observed price of the $k$-th input for the $i$-th firm at time $t, D_{s t}$ is a $0-1$ dummy variable taking the value of 1 if at time $t$ the $s$-th change of the electricity liberalization has been implemented $(s=1,2$, 3 ) and zero otherwise, $t$ is a time trend, thermal ${ }_{i t}$ is the ratio of thermal power generation to hydroelectric generation for the $i$-th firm at time $t$, nuclear $_{i t}$ is the ratio of nuclear power generation to hydroelectric generation for the $i$-th firm at time $t$, new $w_{i t}$ is the ratio of new energy generation to hydroelectric generation for the $i$-th firm at time $t, \alpha_{j}, \beta_{k}, \gamma_{j l}, \delta_{k m}, \rho_{j k}, \tau_{s}, \varphi_{\text {thermal }}, \varphi_{\text {nuclear }}$, and $\varphi_{\text {new }}$ are coefficients to be estimated, $u_{i t}$ is the inefficiency term for the $i$-th firm at time $t$, and $v_{i t}$ is a standard disturbance. In this model, it is assumed that all firms have the same production technology.

\subsection{Method for Estimating Economies of Scale}

When a 2 output cost function is assumed, the economies of scale for $y_{i t}$ is defined as

$$
s_{\text {oit }}=\frac{M C_{i t}}{A C_{i t}}=\frac{\partial T C_{i t}}{\partial y_{\text {oit }}} \cdot \frac{y_{\text {oit }}}{T C_{i t}}=\frac{\partial \ln T C_{i t}}{\partial \ln y_{\text {oit }}}
$$

where $s_{\text {oit }}$ is the economies of scale for the o-th output, $M C_{i t}$ is marginal cost, and $A C_{i t}$ is average cost. Equation (3) means that there are economies of scale when average cost is larger than marginal cost. Therefore, when $s_{\text {oit }}$ is larger than 1 , there are no economies of scale. When $s_{\text {oit }}$ is less than 1 , there are economies of scale.

In the case of this paper, the economies of scale for $y_{1 i t}$ and $y_{2 i t}$ are defined as

$$
\begin{gathered}
s_{1 i t}=\alpha_{1}+\gamma_{11} \ln y_{1 i t}+\gamma_{12} \ln y_{2 i t}+\rho_{11} \ln p_{1 i t}+\rho_{12} \ln p_{2 i t}+\rho_{13} \ln p_{3 i t} \\
s_{2 i t}=\alpha_{2}+\gamma_{22} \ln y_{1 i t}+\gamma_{12} \ln y_{1 i t}+\rho_{21} \ln p_{1 i t}+\rho_{22} \ln p_{2 i t}+\rho_{23} \ln p_{3 i t}
\end{gathered}
$$

In the case of two outputs, the overall economies of scale are measured as follows:

$$
S C L_{i t}=\frac{M C_{i t}}{A C_{i t}}=M C_{i t} \cdot \frac{y_{i t}}{T C_{i t}}=\frac{y_{i t} M C_{i t}}{T C_{i t}}=\frac{y_{1 i t} \frac{\partial \ln T C_{i t}}{\partial \ln y_{1 i t}}+y_{2 i t} \frac{\partial \ln T C_{i t}}{\partial \ln y_{1 i t}}}{T C_{i t}}
$$

When (6) is larger than 1 , there are no economies of scale. On the other hand, when (6) is less than 1, there 
are economies of scale. Combining (3) and (6), the overall economies of scale can be defined as

$$
S C L_{i t}=\frac{y_{1 i t} S_{1 i t}+y_{2 i t} S_{2 i t}}{T C_{i t}}
$$

\subsection{Method for Estimating Economies of Scope}

Baumol, Panzar and Willing (1982) [11] define economies of scope as being complementary if

$$
\frac{\partial^{2} T C_{i t}}{\partial y_{1 i t} \partial y_{2 i t}}<0
$$

One interpretation of Equation (8) is that for costs to be complementary the marginal cost of each output will decline when the amount of the other output increases. The second derivative on the left hand side of Equation (8) can be computed using (1) as:

$$
\frac{\partial^{2} T C_{i t}}{\partial y_{1 i t} \partial y_{2 i t}}=\left(\frac{T C_{i t}}{y_{1 i t} y_{2 i t}}\right)\left[\frac{\partial \ln T C_{i t}}{\partial \ln y_{1 i t} \partial \ln y_{2 i t}}+\frac{\partial \ln T C_{i t}}{\partial \ln y_{1 i t}} \cdot \frac{\partial \ln T C_{i t}}{\partial \ln y_{2 i t}}\right]=\left(\frac{T C_{i t}}{y_{1 i t} y_{2 i t}}\right)\left[\gamma_{12}+s_{1 i t} \cdot s_{2 i t}\right] \text {. }
$$

In Equation (9), $\left(\frac{T C_{12}}{y_{1} y_{2}}\right)$ is always positive because $T C_{12}, y_{1}$, and $y_{2}$ are all positive. Therefore, to see if (9) is satisfied, it is only necessary to examine the sign of the following expression:

$$
S C P_{i t 12}=\gamma_{12}+s_{1 i t} \cdot s_{2 i t}
$$

Since this is a function of unknown parameters and the values of the explanatory variables, it needs to be evaluated using estimates of the paramters and the sample values of the explanatory variables.

\subsection{Estimated Model}

Equation (1) with $u_{i t}=0$ gives rise to a simple pooling model was given. Since the data being used to estimate the cost function are panel data,it is natural to estimate Equation (1) allowing for inidvidual firm effects that are either fixed and random effects. In this case, $u_{i t}$ is a time-invariant random variable that is correlated with the explanatory variables for the fixed effects model. In addition to these standard panel models, some stochastic frontier models are estimated in this study to allow for possible existence of stochastic inefficiencies. To try and capture any cost inefficiencies, four models are assumed: the pooling Stochastic Frontier (SF) model; the random-effects SF model; the fixed-effects SF model; and the Battese and Coelli (1992) Time Varying Stochastic Frontier (TV-SF) model [12]. The estimated models are as follows;

Pooling Stochastic Frontier Model

$$
\ln T C_{i t}=f(\cdot)+u_{i t}+v_{i t}, \quad u_{i t} \sim H N\left(0, \sigma_{\mu}^{2}\right), v_{i t} \sim N\left(0, \sigma_{v}^{2}\right),
$$

Tine Invariant SF Model

$$
\ln T C_{i t}=f(\cdot)+u_{i}+v_{i t}, \quad u_{i} \sim H N\left(0, \sigma_{\mu}^{2}\right), v_{i t} \sim N\left(0, \sigma_{v}^{2}\right),
$$

Fixed-Effects SF Model

$$
\ln T C_{i t}=f(\cdot)+\zeta_{i}+u_{i}+v_{i t}, \quad u_{i} \sim H N\left(0, \sigma_{\mu}^{2}\right), v_{i t} \sim N\left(0, \sigma_{v}^{2}\right),
$$

Battese and Coelli Time Varying SF Model

$$
\ln T C_{i t}=f(\cdot)+u_{i t}+v_{i t}, u_{i t}=\exp \left\{-\eta\left(t-T_{i}\right)\right\} u_{i}, u_{i} \sim H N\left(0, \sigma_{\mu}^{2}\right), v_{i t} \sim N\left(0, \sigma_{v}^{2}\right),
$$

where $u_{i}$, and $u_{i t}$ are measures of technical inefficiency, $v_{i t}$ is standard disturbance, $\zeta_{i}$ is the individual fixed effect, $T_{i}$ is the number of observations on firm $i$ in the panel data set, $N$ and $H N$ denote a nornal distribution and a half normal distribution, respectively. The difference between models (11), (12), (13) and (14) lies in the specification of the inefficiency term. Models (11), (13), and (14) take no account of the panel nature of the data, while model (12) does. It should be noted that models (11) and (12) are non-nested models, while 
Equation (12) can be obtained as a special case of Equation (13) by imposing the restriction $\zeta_{i}=0$ for all $i$, and as a special case of Equation (14) by imposing the restriction $\eta=0$. The pooling model can be obtained as a special case of Equations (11) and (12) by imposing the restriction $\sigma_{\mu}^{2}=0$. If $\sigma_{\mu}^{2}=0$ in all these models, then the pooling model is chosen. The standard fixed effects models is nested within Equation (13) and can be obtained by imposing $\sigma_{\mu}^{2}=0$. The standard random effects model and any one of the stochastic frontier models are non-nested models.

\section{Data}

Data on the corporate accounts of the ten general electricity utilities are drawn from the "Electricity Statistics Information (Denryoku Toukeijouhou)" published by the Federation of Electric Power Companies of Japan. Though ten general electricitiy utilities have existed in Japan since 1970, Okinawa Electric Power Company is excluded from the analysis in this study. The reason for this is that electricity production by Okinawa Electric has some important characteristics that differ from other companies. For example, the scale of electricity production at Okinawa Electric is much smaller than at the other companies. In addition, Okinawa Electric is the only general electricity utility not using nuclear energy for electric power generation. Finally, the prefecture of Okinawa is made up of a number of small islands where Okinawa Electric is obliged to generate and supply electricity. As a result, it is thought that Okinawa Electric Power Company has a unique production function and a unique cost function. Hence, a balanced panel data set consisting of annual data on the other nine general electricitiy utilities from 1970 to 2010 is used.

$T C_{12}$ is total costs measured in million yen. The output in the electricity generation sector, $y_{1 i t}$, is defined as the total quantity of electric power sold to consumers in the lighting and power sectors (MWh). The output in the transmission sector, $y_{2 i t}$, is defined as the length in kilometers of the transmission route including both overhead and underground routes. The unit fuel cost, $p_{1 i t}$ (million yen), is defined as

$$
p_{1 i t}=\frac{(\text { total fuel expenses })_{i t}}{(\text { total quantity of fuel inputs })_{i t}} .
$$

The gross fixed capital is employed for the cost of capital, $p_{2 i t}$ (million yen). It is defined as

$$
\begin{gathered}
p_{2 i t}=\left(D E_{i t} / G F C_{i t-1}\right)+L P R_{t}, \\
G F C_{i t-1}=E U F A_{i t-1}+F A P_{i t-1}+I A_{i t-1}
\end{gathered}
$$

where $p_{2 i t}$ is the cost of capital for the $i$-th firm in year $t, D E_{i t}$ is the depreciation expenses for the $i$-th firm in year $t, G F C_{i t-1}$ is the gross fixed capital for the $i$-th firm in year $t-1, L P R_{t}$ is the long-term prime rate for loans made by the main Japanese banks in year $t, E U F A_{i t-1}$ is the fixed assets for the $i$-th firm in year $t-1, F A P_{i t-1}$ is the fixed assets in process for the $i$-th firm in year $t-1$, and $I A_{i t-1}$ is investment and other assets for the $i$-th firm in year $t-1$. Data on the long-term prime rate for loans made by the main Japanese banks are drawn from the "Bank of Japan Statistics" published by Bank of Japan. The personal expenses per worker per year, $p_{3 i t}$ (million yen), is defined as

$$
p_{3 i t}=\frac{(\text { personal expenses })_{i t}}{(\text { the number of workers })_{i t}} .
$$

$D_{1}$ is a 0 - 1 dummy variable taking the value of 1 in 1995-2010, $D_{2}$ is a 0 - 1 dummy variable taking the value of 1 in 2001-2010, and $D_{3}$ is a 0 - 1 dummy variable taking the value of 1 in 2004-2010. These three dummy variables correspond to the three entry related liberalizations discussed in Section 2.

Table 2 provides desciptive statistics on all the relevant variables. The variables LNC, LNY1, LNY2, LNP1, LNP2, and LNP3 in Table 2 refer to the natural logs of $T C_{i t}, y_{1 i t}, y_{2 i t}, p_{1 i t}, p_{2 i t}, p_{3 i t}$, respectively. The variable LNT in Table 2 refers to the natural log of the year. The variables THERMAL, NUCLEAR, and NEW in Table 2 are the ratio of the quantities of electricity generation of thermal power, nuclear power, and new energy to hydraulic power, respectively.

\section{Results and Discussion}

LIMDEP 10 (Greene (2005) [13]) is used to obtain all the estimates presented in Table 3. With the exception of 
Table 2. Descriptive statistics.

\begin{tabular}{ccccc}
\hline Variable & Mean & Std. Dev. & Minimum & Maximum \\
\hline LNC & 13.588 & 0.992 & 10.874 & 15.682 \\
LNY1 & 17.684 & 0.847 & 15.817 & 19.511 \\
LNY2 & 8.977 & 0.594 & 7.829 & 9.957 \\
LNP1 & -3.734 & 0.546 & -5.256 & -2.685 \\
LNP2 & 1.543 & 0.631 & 0.472 & 2.299 \\
LNP3 & 2.041 & 0.505 & 0.676 & 2.751 \\
$D_{1}$ & 0.390 & 0.488 & 0 & 1 \\
$D_{2}$ & 0.244 & 0.430 & 0 & 1 \\
$D_{3}$ & 0.171 & 0.377 & 0 & 1 \\
LNT & 7.596 & 0.006 & 7.586 & 7.606 \\
THERMAL & 5.699 & 3.159 & 0.537 & 17.145 \\
NUCLEAR & 2.639 & 2.791 & 0.000 & 12.955 \\
NEW & 0.026 & 0.083 & 0.000 & 0.462 \\
\hline
\end{tabular}

Table 3. Estimated results.

\begin{tabular}{|c|c|c|c|c|}
\hline & Model A & Model B & Model C & Model D \\
\hline & Pooling & Random-effects & Fixed-effects & Pooling SF \\
\hline \multirow[t]{2}{*}{ Constant } & $-211.725^{* * *}$ & $-189.279^{* * *}$ & & $-186.749^{* * *}$ \\
\hline & (45.918) & (44.125) & & (42.011) \\
\hline \multirow[t]{2}{*}{ LNY1 } & $1.828^{* * *}$ & 0.730 & 0.618 & $1.516^{* * *}$ \\
\hline & $(0.598)$ & $(0.972)$ & (1.507) & (0.549) \\
\hline \multirow[t]{2}{*}{ LNY2 } & $-4.482^{* * * *}$ & -1.398 & 0.002 & $-3.916^{* * *}$ \\
\hline & (0.998) & (1.260) & (1.989) & (0.952) \\
\hline \multirow[t]{2}{*}{ LNP1 } & 0.875 & 0.786 & $1.111^{* *}$ & $1.005^{*}$ \\
\hline & (0.553) & (0.509) & $(0.520)$ & (0.513) \\
\hline \multirow[t]{2}{*}{ LNP2 } & 0.245 & 0.580 & 0.549 & 0.265 \\
\hline & $(0.581)$ & (0.549) & (0.596) & $(0.516)$ \\
\hline \multirow[t]{2}{*}{ LNP3 } & $1.896^{* *}$ & $1.996^{* *}$ & 0.734 & $2.444^{* * * *}$ \\
\hline & $(0.753)$ & $(0.777)$ & (0.954) & $(0.713)$ \\
\hline \multirow[t]{2}{*}{ LNY1_2 } & $-0.3582^{* * *}$ & -0.146 & -0.030 & $-0.3159^{* * *}$ \\
\hline & (0.093) & $(0.118)$ & $(0.166)$ & $(0.088)$ \\
\hline \multirow[t]{2}{*}{ LNY2_2 } & $-0.61899^{* * *}$ & $-0.39693^{*}$ & -0.006 & $-0.59851^{* * *}$ \\
\hline & (0.190) & $(0.235)$ & (0.349) & $(0.183)$ \\
\hline \multirow[t]{2}{*}{ LNY1LNY2 } & $0.592^{* * * *}$ & $0.304^{*}$ & 0.021 & $0.547^{* * * *}$ \\
\hline & $(0.142)$ & $(0.160)$ & (0.209) & $(0.137)$ \\
\hline \multirow[t]{2}{*}{ LNP1_2 } & $0.236^{* * * *}$ & $0.243^{* * * *}$ & $0.241^{* * * *}$ & $0.251^{* * *}$ \\
\hline & $(0.059)$ & $(0.054)$ & $(0.055)$ & $(0.054)$ \\
\hline \multirow[t]{2}{*}{ LNP2_2 } & 0.032 & 0.000 & 0.042 & 0.019 \\
\hline & $(0.075)$ & $(0.070)$ & $(0.072)$ & $(0.067)$ \\
\hline \multirow[t]{2}{*}{ LNP3_2 } & $-0.315^{* *}$ & $-0.295^{* *}$ & $-0.287^{* *}$ & $-0.378^{* * *}$ \\
\hline & $(0.150)$ & (0.139) & $(0.144)$ & (0.138) \\
\hline LNP1LNP2 & $0.146^{* * *}$ & $0.181^{* * *}$ & $0.218^{* * *}$ & $0.129^{* *}$ \\
\hline
\end{tabular}




\section{Continued}

\begin{tabular}{|c|c|c|c|c|}
\hline & $(0.055)$ & $(0.051)$ & $(0.053)$ & $(0.052)$ \\
\hline \multirow[t]{2}{*}{ LNP2LNP3 } & $0.264^{* * *}$ & $0.281^{* * *}$ & $0.391^{* * *}$ & $0.218^{* *}$ \\
\hline & (0.092) & $(0.087)$ & $(0.092)$ & $(0.086)$ \\
\hline \multirow[t]{2}{*}{ LNP1LNP3 } & 0.054 & 0.069 & 0.062 & 0.067 \\
\hline & $(0.064)$ & $(0.059)$ & $(0.060)$ & $(0.060)$ \\
\hline \multirow[t]{2}{*}{ LNY1LNP1 } & -0.015 & -0.029 & $-0.067^{* *}$ & -0.026 \\
\hline & (0.030) & $(0.027)$ & (0.029) & $(0.028)$ \\
\hline \multirow[t]{2}{*}{ LNY1LNP2 } & $-0.098^{* * *}$ & $-0.078^{* *}$ & -0.036 & $-0.100^{* * *}$ \\
\hline & $(0.036)$ & $(0.036)$ & (0.043) & $(0.031)$ \\
\hline \multirow[t]{2}{*}{ LNY1LNP3 } & 0.018 & -0.008 & 0.025 & -0.006 \\
\hline & $(0.048)$ & $(0.052)$ & $(0.066)$ & $(0.043)$ \\
\hline \multirow[t]{2}{*}{ LNY2LNP1 } & 0.017 & 0.048 & $0.079^{* *}$ & 0.030 \\
\hline & $(0.037)$ & $(0.034)$ & (0.035) & $(0.035)$ \\
\hline \multirow[t]{2}{*}{ LNY2LNP2 } & $0.165^{* * *}$ & $0.104^{* *}$ & 0.004 & $0.172^{* * *}$ \\
\hline & $(0.052)$ & $(0.050)$ & (0.059) & $(0.047)$ \\
\hline \multirow[t]{2}{*}{ LNY2LNP3 } & $-0.162^{* *}$ & $-0.119^{*}$ & -0.063 & $-0.142^{* *}$ \\
\hline & $(0.065)$ & $(0.063)$ & $(0.072)$ & $(0.060)$ \\
\hline \multirow[t]{2}{*}{$D_{1}$} & $-0.070^{* * * *}$ & $-0.066^{* * *}$ & $-0.058^{* *}$ & $-0.072^{* * *}$ \\
\hline & $(0.026)$ & $(0.024)$ & $(0.024)$ & $(0.027)$ \\
\hline \multirow[t]{2}{*}{$D_{2}$} & $-0.153^{* * * *}$ & $-0.141^{* * *}$ & $-0.151^{* * *}$ & $-0.150^{* * * *}$ \\
\hline & (0.025) & $(0.023)$ & $(0.023)$ & (0.023) \\
\hline \multirow[t]{2}{*}{$D_{3}$} & $-0.157^{* * *}$ & $-0.127^{* * *}$ & $-0.120^{* * *}$ & $-0.154^{* * *}$ \\
\hline & $(0.028)$ & $(0.026)$ & $(0.027)$ & $(0.028)$ \\
\hline \multirow[t]{2}{*}{ LNT } & $29.105^{* * *}$ & $25.499^{* * *}$ & $41.691^{* * *}$ & $25.778^{* * *}$ \\
\hline & (5.925) & (5.690) & $(6.851)$ & (5.435) \\
\hline \multirow[t]{2}{*}{ THERMAL } & $0.007^{* * *}$ & 0.002 & 0.004 & $0.007^{* * *}$ \\
\hline & $(0.002)$ & $(0.003)$ & (0.0039 & $(0.002)$ \\
\hline \multirow[t]{2}{*}{ NUCLEAR } & -0.002 & $-0.010^{* * * *}$ & $-0.008^{*}$ & 0.000 \\
\hline & (0.003) & $(0.004)$ & $(0.004)$ & (0.003) \\
\hline \multirow[t]{2}{*}{ NEW } & 0.055 & $0.212^{* *}$ & $0.366^{* * *}$ & 0.009 \\
\hline & $(0.082)$ & $(0.084)$ & (0.091) & $(0.077)$ \\
\hline$\sigma_{u}$ & & & & 0.103 \\
\hline$\sigma_{v}^{2}$ & & & & 0.002 \\
\hline$\sigma_{u}^{2}$ & & & & 0.011 \\
\hline \multirow[t]{2}{*}{$\sigma=\sqrt{\sigma_{v}^{2} / \sigma_{u}^{2}}$} & & & & $0.114^{* * *}$ \\
\hline & & & & $(0.000)$ \\
\hline \multirow[t]{2}{*}{$\lambda=\sigma_{u} / \sigma_{v}$} & & & & $2.132^{* * *}$ \\
\hline & & & & $(0.274)$ \\
\hline Log likelihood & 416.887 & 425.997 & 456.415 & 421.3133 \\
\hline
\end{tabular}

a. For each explanatory variable and $\lambda$, the first line reports the estimated coefficient, and the second line reports thestandard error. b. ${ }^{*},{ }^{* *}$ and ${ }^{* * *}$ denote significance at the $10 \%, 5 \%$ and $1 \%$ levels, respectively. 
the pooling stochastic frontier model (Equation (11), and denoted Model D in Table 3). Estimates of the stochastic frontier models could not be obtained because the distribution of the estimated inefficiencies are not consist with the assumptions. In all models in Table 3 (Models A - D), all of the estimated coefficients of three dummy variables associated with the electricity liberalization are negative and significant. This suggests that the three entry liberalizations have had some impact in cutting costs. The estimated coefficients associated with the time trend are positive and significant in all models. While technical innovation might be expected to lead to reductions in the cost of generation over time, stricter environmental and safety standards can be expected to have increased production costs over time. The coefficients of the ratio of thermal power, nuclear power, and new energy to hydroelectric power differ between the non-frontier models and the frontier models. In both nonfrontier models and frontier models, the coefficients of thermal power are positive and significant in Models A and D, but insignificant in Models B and C. Before the coefficients of nuclear power and new energy are discussed, the models are specified.

In choosing between the usual panel models (Model A, B, and C) and frontier model (Models D), the usual panel models are supported forthe following reason. In Model $\mathrm{D}$, the estimate of $\lambda$ are positive and significant in all cases, and this suggests that there is a statistically significant inefficiency. Nevertheless, the value of the maximized loglikelihood of Model D is smaller than the value forthe usual panel models (Model B and Model C). In addition to this, the assumption that the cost function is increasing function in $y_{1 i t}, y_{2 i t}, p_{1 i t}, p_{2 i t}$, and $p_{3 i t}$ issatisfied only in some samples. For Model D, Table 4 reports some descriptive statistics for the estimates of the cost efficiencies for each power utility. The cost efficiencies are calculated as $\exp \left(-u_{i t}\right)$, using the estimates of the inefficiency terms. The cost efficiencies range from 0 to 1 , with larger values of cost efficiency meaning a firm is more efficient. The largest value of cost efficiency is 0.983 (Tohoku Electric), while the smallest value is 0.769 (Chugoku Electric). All values of the average cost efficiency for each electricity company exceed 0.9 . This suggests that all companies are quite cost efficient.

In choosing among the usual panel models (Models A, B, and C), the fixed-effects model (Model) C is supported since the $\mathrm{F}$ test testing the null hypothesis that individual fixed effects are absent rejects the pooling models with a p-value of 0.000 , and the log likelihood of the fixed-effects model is the largest among the usual panel models. LIMDEP 10 could not obtain the result of the Hausman test because the inverse of the covariance matrix for Hausman test could not be calculated. In the fixed-effect model, the assumption that the cost function is an increasing function in $y_{1 i t}, y_{2 i t}, p_{1 i t}, p_{2 i t}$, and $p_{3 i t}$ is satisfied in the almost samples except for $y_{2 i t}$. Because the estimated coefficient of nuclear power is negative and significant in Model $\mathrm{C}$, the use of nuclear power seems to have contributed to reducing costs. Because the estimated coefficient of new energy is positive and significant in Model C, the use of new energy seems to increase costs.

Estimates from the fixed effects model (Model C) are used to determine whether economies of scale exist and whether economies of scope exist Table 5 reports some descriptive statistics for the estimates of economies of scale. Since the mean of the estimates of $s_{1 i t}$ for each power utility is under 1, these results suggest that econo-

\begin{tabular}{ccccc}
\hline \multicolumn{6}{l}{ Table 4. Estimates of r cost efficiencies: descriptive statistics. } \\
\hline Firm & Mean & Std.Dev. & Minimum & Maximum \\
\hline Hokkaido & 0.926 & 0.049 & 0.814 & 0.982 \\
Tohoku & 0.901 & 0.061 & 0.777 & 0.983 \\
Tokyo & 0.922 & 0.038 & 0.82 & 0.974 \\
Chubu & 0.937 & 0.024 & 0.863 & 0.978 \\
Hokuriku & 0.937 & 0.035 & 0.812 & 0.980 \\
Kansai & 0.927 & 0.036 & 0.829 & 0.979 \\
Chugoku & 0.910 & 0.055 & 0.769 & 0.980 \\
Shikoku & 0.908 & 0.040 & 0.790 & 0.974 \\
Kyushu & 0.935 & 0.042 & 0.772 & 0.977 \\
All & 0.923 & 0.045 & 0.769 & 0.983 \\
\hline
\end{tabular}


Table 5. Estimates of economies of scale.

\begin{tabular}{ccccc}
\hline \multicolumn{5}{c}{ Economies of scale for electricity generation } \\
\hline Firm & Mean & Std.Dev. & Minimum & Maximum \\
\hline All & 0.522 & 0.047 & 0.411 & 0.630 \\
\hline \multicolumn{5}{c}{ Economies of scale for electricity transmission } \\
\hline Firm & Mean & Std.Dev. & Minimum & Maximum \\
\hline All & -0.098 & 0.046 & -0.214 & 0.014 \\
\hline & & & & \\
\hline Firm & Mean & Std.Dev. & Minimum & Maximum \\
\hline Hokkaido & 35.658 & 18.892 & 19.553 & 95.343 \\
Tohoku & 32.805 & 19.732 & 17.106 & 97.198 \\
Tokyo & 31.610 & 16.472 & 16.815 & 83.033 \\
Chubu & 35.346 & 18.409 & 18.168 & 93.520 \\
\hline Hokuriku & 38.365 & 21.476 & 20.890 & 108.251 \\
Kansai & 34.213 & 18.421 & 19.016 & 94.478 \\
Chugoku & 35.474 & 19.405 & 17.694 & 94.531 \\
Shikoku & 32.888 & 17.845 & 18.511 & 89.100 \\
\hline Kyushu & 32.885 & 15.050 & 18.201 & 77.712 \\
All & 34.360 & 18.397 & 16.815 & \\
\hline & & & \\
\hline & & & \\
\hline
\end{tabular}

mies of scope exist in the generation sector. The problem is that the mean estimates of $s_{2 i t}$ for each power utility is negative. One possible reason for this is that the cost of transmission includes investment in plant and equipment. Since the mean of the estimates of the ovrall economies of scale, $S C L_{i t}$, for each power utility is over 1, these results suggest that overall economies of scope does not exist.

Figure 2 displays estimates of the overall economies of scale for each power utility from 1970 to 2010. Movements of the overall economies of scale for all companies are more or less the same during the period. In the 1970s, $S C L_{i t}$ declined rapidly, and then, $S C L_{i t}$ has been increasing slowly. The estmated value of $S C L_{i t}$ exceeds 1 throughout the period. Though this means that overall economies scale have not been existed during this period, the econoies of scales for generation and transmission was improved in the 1970s. In the 1970s, Japan started to convert to nuclear power in earnest after the oil shock. It is considered that the saving on oil use contributed to the economies of scales.

Table 6 reports some descriptive statistics for estimates of $S C P_{12}$ for each power utility. Since the mean of the estimates of $S C P_{12}$ for each power utility is negative, these results suggest that economies of scope exist between the generation sector and tranmission sector for electricity on average.

\section{Concluding Remarks}

This study measures the impact of liberalization on the cost efficiency of electricity production in Japan, and examines whether or not economies of scale and economies of scope exist between electricity generation and transmission. The estimation results suggest that production costs have fallen significantly following each of the three entry-related liberalizations, and support the existence of economies of scope. While the existence of overall economies of scale is not supported, economies of scale become much stronger in the 1970s. One notable result is that the estimated coefficient of the time trend is positive. This may mean that there are factors which have reduced cost efficiencies. There is a possibility of improving the inefficient factors by further liberalization 


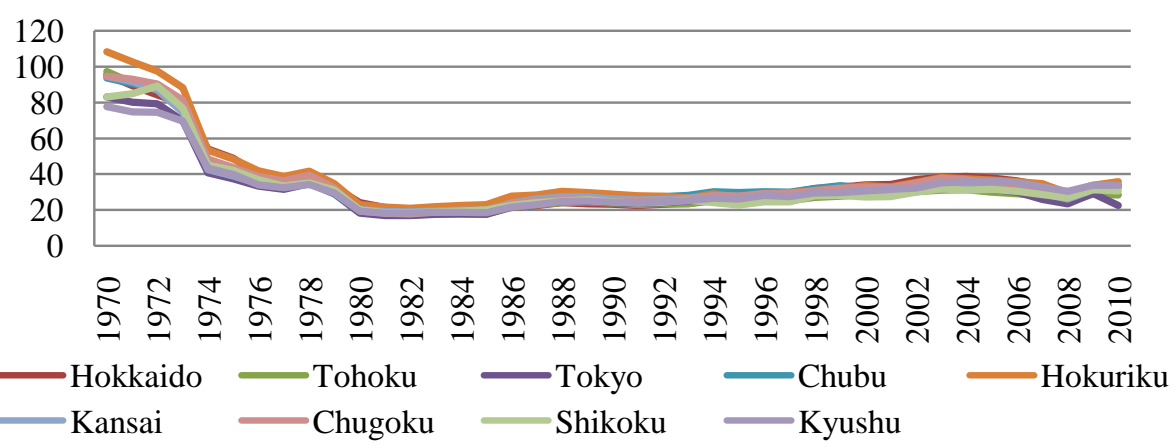

Figure 2. Overall economies of scale over time.

Table 6. Estimated results for economies of scope.

\begin{tabular}{ccccc}
\hline Firm & Mean & Std.Dev. & Minimum & Maximum \\
\hline Hokkaido & -0.050 & 0.023 & -0.093 & -0.008 \\
Tohoku & -0.034 & 0.025 & -0.071 & 0.014 \\
Tokyo & -0.012 & 0.020 & -0.041 & 0.027 \\
Chubu & -0.026 & 0.026 & -0.066 & 0.021 \\
Hokuriku & -0.050 & 0.035 & -0.114 & 0.013 \\
Kansai & -0.013 & 0.021 & -0.047 & 0.025 \\
Chugoku & -0.037 & 0.028 & -0.079 & 0.017 \\
Shikoku & -0.037 & 0.024 & -0.078 & 0.013 \\
Kyushu & -0.031 & 0.023 & -0.061 & 0.014 \\
All & -0.032 & 0.028 & -0.114 & 0.027 \\
\hline
\end{tabular}

in the electricity generation and distribution sectors. The structural separation of the transmission sector of electricity from the generation of electric power, which has been discussed recently, is one example of a further liberalization. However, considering the existence of the scope of economies between the generation sector and the transmission sector, other kinds of liberalization should be introduced.

\section{Acknowledgements}

I would like to thank Hiroki Kawai, Colin McKenzie, Ryo Nakajima, Tatsuo Tanaka, and two anonymous referees for their helpful comments and suggestions.

\section{References}

[1] Taniguchi, M. (2013) The Impact of Liberalization on the Production of Electricity in Japan, Keio/Kyoto Joined Global Center of Excellence Program, Raising Market Quality-Integrated Design of Market Infrastructure, DP2012-027. http://ies.keio.ac.jp/old_project/old/gcoe-econbus/pdf/dp/DP2012-027.pdf

[2] Taniguchi, M. (2013) The Impact of Liberalization on the Production of Electricity in Japan. The Proceedings of the International Conference on Applied Economics (ICOAE) 2013, Istanbul, 27-29 June 2013, 712-721. http://www.sciencedirect.com/science/article/pii/S221256711300083X

[3] Goto, M. and Inoue, T. (2012) Economic Analysis of Structural Reforms of Electricity Industry: Investigation of Cost Structure of Japanese Electricity (Denkijigyou no KouzoukaikakunikansuruKeizaiseibunseki: WagakuniDenkijigyou no Hiyoukouzoubunseki). Central Research Institute of Electric Power Industry Research Report, Paper\#Y11009. (in Japanese) http://criepi.denken.or.jp/jp/kenkikaku/report/download/PwquwpH8FPLMWnKfJ2Cyy0CZVgAfsMNW/report.pdf

[4] Kuwabara, T. and Ida, T. (2000) The Panel Data Analysis of the Japanese Electric Power Industry (Nihon no 
Denryokusangyou no Panerudeta Bunseki), Kouekijigyoukenkyu. KouekiJigyouKenkyuu, 52, 71-82. (in Japanese)

[5] Nemoto, J. and Goto, M. (2006) Measurement of Technical and Allocative Efficiencies Using a CES Cost Frontier: A Benchmarking Study of Japanese Transmission-Distribution Electricity. Empirical Economics, 31, 31-48. http://dx.doi.org/10.1007/s00181-005-0013-x

[6] Kinugasa, T. (2011) Estimating the Degree of Market Competitiveness after Deregulation: An Analysis Using the Translog Production Function for the Japanese Electricity Industry (Kiseikanwago no Shijoukyousoudo no Suitei; Nihon no Denryoku sangyou no Toransurogugata seisan kansuuwomotiita Bunseki). Proceedings of the $68^{\text {th }}$ Conference of Japan Economic Policy Association, Tokyo, 28-29 May 2011. (in Japanese) http://www.komazawa-u.ac.jp/files/880/p37.pdf

[7] Tsutsui, M (2000) Comparison of Intertemporal Technical Efficiency by Sector among Japanese and US Electric Utilities. The Application of Malmquist Index Calculated by DEA, Central Research Institute of Electric Power Industry Research Report, Y99013. (in Japanese with English Abstract) http://criepi.denken.or.jp/jp/kenkikaku/report/download/WUUZBO5d2c4xbfSn82i8CLzwTUZZUQYA/report.pdf

[8] Hattori, T., Jamasb, T. and Pollitt, M. (2005) Electricity Distribution in the UK and Japan: A Comparative Efficiency Analysis 1985-1998. Energy Journal, 26, 23-47. http://dx.doi.org/10.5547/ISSN0195-6574-EJ-Vol26-No2-2

[9] Yamaguchi, S. (2007) The Results and Issues of the Electricity Liberalizations in Japan: A Comparison of Japan to Europe and the US (Denryokujiyuuka no Seika to Kadai: Oubei to Nihon no Hikaku), Issue Brief, No. 595 (in Japanese) http://www.ndl.go.jp/jp/data/publication/issue/0595.pdf

[10] Minister of Economy, Trade and Industry (2011) Material 3: Discussion Points of the Calculations for Electricity Charges (Shiryou 3: DenkiryoukinSanteijou no KakuRontennitsuite). Constructed by Heisei 23 nen 12 gatsu Denkiryoukinseido Unyou no Minaoshinikakaru Yushikisyakaigi Jimukyoku. http://www.meti.go.jp/committee/kenkyukai/energy/denkiryoukin/003_03_01.pdf

[11] Baumol, W.J., Panzar, J.C. and Willig, R.D. (1982) Contestable Markets and the Theory of Industry Structure. Harcourt Brace Jovanovich, New York.

[12] Battese, G.E. and Coelli, T.J. (1992) Frontier Production Functions, Technical Efficiency and Panel Data: With Application to Paddy Farmers in India. Journal of Productivity Analysis, 3, 153-169. http://dx.doi.org/10.1007/BF00158774

[13] Greene, W. (2005) Fixed and Random Effects in Stochastic Frontier Models. Journal of Productivity Analysis, $23,7-35$. http://dx.doi.org/10.1007/s11123-004-8545-1 